\title{
Accountability no Mato Grosso do Sul: um retrato a partir dos portais eletrônicos municipais
}

\author{
Accountability in Mato Grosso do Sul: a portrait from municipal websites
}

Accountability en Mato Grosso do Sul: un retrato a partir de los portales electrónicos municipales Pós-graduanda em Contabilidade Gerencial e Estratégica pela Faculdade de Educação, Tecnologia e Administração de Caarapó (FETAC) http://lattes.cnpq.br/8535351376285322 https://orcid.org/0000-0002-8915-8917 annapaula.svieira@gmail.com

Andréia dos Santos Mendonça Graduada em Ciências Contábeis pela Faculdade de Educação, Tecnologia e Administração de Caarapó (FETAC) http://lattes.cnpq.br/0308570865801084 https://orcid.org/0000-0001-6326-5987 andreiamendonssa@gmail.com

Rafael Todescato Cavalheiro Mestre em Agronegócios pela Universidade Federal da Grande Dourados (UFGD) Professor Adjunto e Coordenador do curso de Ciências Contábeis (FETAC) http://lattes.cnpq.br/181814184928288 https://orcid.org/0000-0002-3468-5357 rafaeltodescato@hotmail.com

Andréia Maria Kremer Doutoranda em Administração pela Universidade Federal de Mato Grosso do Sul (UFMS Professora Assistente do curso de Administração (FETAC) http://lattes.cnpq.br/9977778825540242 https://orcid.org/0000-0002-7162-246X andreiakremer@hotmail.com

Resumo: Com o objetivo de verificar a capacidade de accountability dos portais eletrônicos municipais do estado do Mato Grosso do Sul (MS), foi realizada uma pesquisa descritiva com abordagem qualitativa nos portais eletrônicos das 79 prefeituras. Como técnica de coleta de dados, foi utilizado o protocolo de busca, tendo como referência o estudo de Raupp e Pinho (2013). Os municípios foram classificados de acordo com a capacidade alta, média, baixa ou nula nas dimensões de prestação de contas, transparência e participação da accountability. As evidências revelam que nas dimensões da transparência e participação, os portais apresentam bons resultados para a construção da accountability. Contudo, quanto à prestação de contas, a maioria das prefeituras municipais não cumpre a legislação de maneira efetiva e tampouco divulga informações financeiras com enfoque nos stakeholders, demonstrando que ainda há um longo caminho a ser percorrido para que de fato exista uma cultura de accountability no MS.

Palavras-chave: Prefeituras municipais, website governamental.

\begin{abstract}
In order to verify the accountability capacity of municipal websites in the state of Mato Grosso do Sul, a descriptive research was carried out with a qualitative approach in the websites of the 79 city halls of the state. The search protoco was used to collect data, in accordance to a study by Raupp and Pinho (2013). The municipalities were classified according to a high, medium, low or null capacity of accountability, transparency and participation of accountability. The analysis reveals that regarding transparency and participation the websites present good results for the construction of accountability. However, as far as answerability is concerned, most local governments do not effectively comply with legislation and do not disclose financial information with a stakeholder focus, demonstrating that there is still a long way to go in order to have a culture of accountability in the state of Mato Grosso do Sul.
\end{abstract}

Keywords: Municipalities, Governmental website.

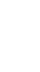

Resumen: Con el objetivo de verificar la capacidad de accountability de los portales electrónicos municipales del estado de Mato Grosso do Sul (MS), se realizó una investigación descriptiva con abordaje cualitativo en los portales electrónicos de las 79 prefecturas del MS. Como técnica de recolección de datos se utilizó el protocolo de búsqueda, teniendo como referencia el estudio de Raupp y Pinho (2013). Los municipios fueron clasificados de acuerdo con la capacidad alta, media, baja o nula en las dimensiones de rendición de cuentas, transparencia y participación de la accountability. Las evidencias revelan que en las dimensiones de la transparencia y participación los portales presentan buenos resultados para la construcción de la accountability. Sin embargo, en cuanto a la rendición de cuentas, la mayoría de las alcaldías municipales no cumplen la legislación de manera efectiva y tampoco divulgan informaciones financieras con enfoque en los stakeholders, demostrando que todavía hay un largo camino a recorrer para que de hecho exista una cultura de accountability en el MS.

Palabras clave: Ayuntamientos, sitio web gubernamental.

Texto completo em português: http://www.apgs.ufv.br Full text in Portuguese: http://www.apgs.ufv.br

\section{Introdução}

Toda informação a respeito da administração pública deve ser divulgada pelos gestores, possibilitando o controle social e a interação entre sociedade e gestão pública. Contudo, não se trata apenas de divulgar, mas divulgar com clareza, qualidade e tempestividade (Dantas, Zendersky, \& Niyama, 2005). Na busca pela ampliação ou recuperação da legitimidade de seus atos e da minimização dos custos políticos, as entidades públicas evidenciam informações financeiras compulsórias e voluntárias, para atender às exigências dos órgãos fiscalizadores e para permitir que a sociedade acompanhe os resultados da gestão pública (Beuren \& Söthe, 2009).
No Brasil, as entidades públicas devem cumprir as imposições legais estabelecidas pela Lei Complementar n 101/2000 (Lei de Responsabilidade Fiscal), Lei Complementar no 131/2009 (Lei da Transparência) e Lei no 12.527/2011 (Lei de Acesso à Informação). Tais dispositivos legais iniciaram um ciclo de mudanças na relação entre cidadão e gestor público (Bairral, Silva, \& Alves, 2015) e são considerados mecanismos que apoiam a construção de uma cultura de accountability, haja vista que reforçam e exigem que os resultados da administração pública sejam apresentados aos cidadãos de forma clara e simples, com informações de fácil acesso e entendimento.

A complexa interação entre sociedade, iniciativa privada e instituições públicas tem como instrumentos facilitadores as 
tecnologias da informação e comunicação (Braga, Alves, Figueiredo \& Santos, 2008; Janssen, Charalabidis \& Zuiderwijk, 2012; Licht, 2014; Torres, Pina \& Acerete, 2006), com destaque para as mídias sociais e portais eletrônicos. As mídias sociais, além de representarem boas práticas de governança da administração pública, possibilitam maior transparência e podem resultar em melhor comunicação e participação da sociedade no exercício da cidadania (Picazo-Vela, Gutiérrez-Martínez \& Luna-Reyes, 2012). Além de promover uma redução no nível de corrupção governamental (Andersen, 2009; Lupu \& Lazăr, 2015; Shim \& Eom, 2008), os portais eletrônicos são capazes de aproximar cidadãos e governantes, promovendo a democracia e a accountability (Raupp, 2011).

Nesse contexto, devido ao aumento das estruturas de controle social e do exercício da cidadania nos últimos anos (Raupp, 2016), as discussões acadêmicas sobre a accountability representam uma importante contribuição para a sociedade e para a administração pública de modo geral. Medir a transparência e o grau de accountability dos governos locais tem se mostrado cada vez mais relevante, haja vista que o monitoramento e controle geralmente não são tão fortes neste nível governamental e, como eles são responsáveis por prestar serviços essenciais à população, a falta de conduta e a má administração no governo local têm grande impacto na vida das pessoas (N. F. Cruz \& Marques, 2014).

A capacidade de promoção da accountability por meio de portais eletrônicos tem sido agenda de pesquisa no cenário científico nacional e internacional (Agostineto \& Raupp, 2010; Andrade, Raupp \& Pinho, 2017; C. F. Cruz, Ferreira, Silva \& Macedo, 2012; C. F. Cruz, Silva \& Santos, 2009; N. F. Cruz, Tavares, Marques, Jorge \& de Sousa, 2016; Jalón, Heras \& Agudo, 2017; Pinho, 2008; Raupp, 2014a, 2016; Raupp \& Pinho, 2013; Rocha, 2013; Sacramento \& Pinho, 2007; Simelio, Ginesta, Vela \& Corcoy, 2017). Contudo, apesar de o tema ser relevante e suscitar interesse da academia, verifica-se que poucos estudos se debruçaram sobre a análise dos portais eletrônicos municipais, principalmente no interior do Brasil. Por isso, este estudo tem por objetivo verificar a capacidade de accountability dos portais eletrônicos municipais do estado do Mato Grosso do Sul (MS).

Os resultados aqui apresentados contribuem para 0 preenchimento dessa lacuna na produção científica e contribuem também para o desenvolvimento de uma cultura de accountability no Brasil, pois retratam o comportamento dos municípios sul-matogrossenses no que tange às dimensões da transparência, participação e prestação de contas. N. F. Cruz et al. (2016) afirmam que os efeitos positivos das mídias e portais eletrônicos nas práticas governamentais dependem da visibilidade e do reconhecimento do seu papel por parte dos stakeholders, em particular das autoridades locais e da sociedade em geral, o que reitera a importância desse estudo.

\section{Accountability}

Os princípios da eficiência, efetividade e transparência são a base da Governança Pública (Hwang \& Akdede, 2011). De acordo com Oliveira e Pisa (2015), o conceito de governança pública envolve transparência, prestação de contas, ética, integridade, legalidade e participação social nas decisões. Nesse sentido, a accountability pode reforçar a democracia e melhorar as práticas de controle e gestão na administração pública (Rodríguez-Bolívar, Navarro-Galera \& Alcaide-Muñoz, 2015). Para Campos (1990), a accountability é entendida como uma questão de democracia, pois quanto mais avançado o estágio democrático do país, maior o interesse da sociedade por essa temática.

O conceito de accountability surge do padrão de relacionamento entre entidades públicas e sociedade, pautando-se na relação de interesse do Estado e das necessidades do cidadão (Mutiganda, 2013). Accountability envolve a responsabilidade objetiva e subjetiva, a transparência, o controle, a obrigação e a responsabilização de quem ocupa um cargo público (Pinho \& Sacramento, 2009). Raupp (2014b) afirma que para que a accountability ocorra de fato, é necessário que sejam disponibilizadas para a sociedade informações da prestação de contas e dos resultados obtidos pelo poder público, gerando assim confiança entre governantes e governados.

No Brasil, em meados de 1975, Campos (1990) deu início a sua pesquisa sobre accountability, visando traduzir esse conceito para o português, de forma clara e inédita. Ao longo dos anos, a autora percebeu que a ausência de uma tradução brasileira derivava de uma pobreza política da população e, consequentemente, de uma falta de atitude do povo, que ao invés de agir, opta por aguardar providências do Estado.

Após quase 20 anos, Pinho e Sacramento (2009) buscaram a definição da palavra accountability em dicionários, para defini-la melhor e trazer novidades à pesquisa de Campos (1990). Os autores constataram que o significado da palavra está relacionado à responsabilidade, à transparência e à obrigação de prestar contas no setor público. Verificaram também que houve avanços nessa discussão, porém a realidade brasileira ainda está longe de construir uma cultura de accountability (Pinho \& Sacramento, 2009), ou seja, na prática, ainda há muito que se fazer "para que se saia da cultura do sigilo para a do acesso" (Bernardes, Santos \& Rover, 2015, p. 789).

A obrigação da prestação de contas da administração pública e o ato de informar a sociedade está disposto na Lei Complementar $n^{\circ} 101$ (2000), também conhecida por Lei de Responsabilidade Fiscal (LRF), na Lei Complementar $n^{\circ} 131$ (2009), conhecida como Lei da Transparência, e na Lei Complementar nº 12.527 (2011), denominada por Lei de Acesso à Informação (LAI).

De acordo com Sacramento e Pinho (2007), a Lei da Responsabilidade Fiscal (LRF) está pautada na transparência, no planejamento, no controle e na responsabilização, sendo praticamente o que regula as contas públicas. O controle, a prestação de contas e a transparência são de suma importância para o controle social e são considerados componentes da 
accountability (Raupp \& Pinho, 2013). A seguir, será apresentado um detalhamento dos componentes de accountability, os quais consistem em Prestação de Contas, Transparência e Participação.

\subsection{Prestação de contas}

A prestação de contas está prevista na Constituição Federal Brasileira em seu artigo 70: "Prestará contas qualquer pessoa física ou jurídica, pública ou privada, que utilize, arrecade, guarde, gerencie ou administre dinheiros, bens e valores públicos ou pelos quais a União responda, ou que, em nome desta, assuma obrigações de natureza pecuniária" (Constituição da República Federativa do Brasil, 2006, p. 29).

Por se tratar de uma obrigação inerente ao gestor público, caso não ocorra, poderá incorrer em sanções (Platt-Neto, F. Cruz, Ensslin \& Ensslin, 2007). A prestação de contas é anual e engloba os Relatórios de Gestão, as Demonstrações Contábeis, os trâmites licitatórios e os pagamentos efetuados. No que diz respeito ao planejamento, devem ser divulgadas a Lei do Plano Plurianual (PPA), Lei de Diretrizes Orçamentárias (LDO) e a Lei Orçamentária Anual (LOA) (Platt-Neto et al., 2007). De acordo com Brusca, Rossi e Aversano (2017), os políticos devem considerar o aprimoramento da elaboração e divulgação das informações contábeis como uma ferramenta para melhorar a gestão pública e reduzir a percepção de corrupção.

A Lei Complementar $n^{\circ} 131$ (2009) estabelece que todos os gastos dos Estados, Municípios e União devem ser divulgados no momento de sua realização. No Brasil, Raupp (2010) evidenciou que a maioria dos portais eletrônicos municipais possuem dificuldades em publicar suas prestações de contas, e as informações são geralmente disponibilizadas de forma parcial ou fora do prazo exigido por lei.

\subsection{Transparência}

A transparência e as iniciativas abertas da gestão pública tornaram-se veículos para aumentar a legitimidade e a confiança no governo, melhorar o envolvimento dos cidadãos e reduzir a corrupção e a má administração dos recursos públicos (N. F. Cruz et al., 2016). No Brasil, a Lei Complementar no 101 (2000) determina que as ações tomadas pelas entidades públicas sejam transparentes, de forma a prevenir riscos e desvios nas contas públicas. A transparência é um dos componentes que têm relação direta com a percepção de corrupção por parte da sociedade
(Brusca et al., 2017), podendo ser capaz de diminuir a corrupção nos órgãos públicos (Andersen, 2009).

Segundo C. F. Cruz et al. (2012), a transparência e o aprimoramento da divulgação das informações a respeito da gestão são considerados cruciais e embasam a boa governança na administração pública. Além disso, a transparência é exigida legalmente e fiscalizada por órgãos competentes, que permitem o acompanhamento e a participação da população.

$\mathrm{Na}$ accountability, a transparência é a categoria mais importante, pois dentro dela é avaliado o desempenho do agente público, que determina as ações e atuação do órgão municipal (Koppell, 2005). A transparência deve ser considerada como um valor central e uma prioridade no relacionamento do governo com a sociedade (Cooper, 2004), e suas práticas de transparência devem ser medidas (N. F. da Cruz et al., 2016).

De acordo com o Manual de Transparência Fiscal publicado pelo Fundo Monetário Internacional (FMI) em 2007, as informações fiscais da administração pública devem possuir clareza e indicar quem são os responsáveis por cada setor público. A administração pública deve informar anualmente receitas, despesas, financiamentos, dívidas, saldos e principais objetivos da entidade, de modo a proteger os direitos dos contribuintes e prestar contas sobre suas atividades (FMI, 2007).

O artigo 48 da Lei de Responsabilidade Fiscal apresenta os instrumentos de transparência da gestão fiscal.

São instrumentos de transparência da gestão fiscal, aos quais será dada ampla divulgação, inclusive em meios eletrônicos de acesso público: os planos, orçamentos e leis de diretrizes orçamentárias; as prestações de contas e o respectivo parecer prévio; o Relatório Resumido da Execução Orçamentária e o Relatório de Gestão Fiscal; e as versões simplificadas desses documentos (BRASIL, 2000 , p. 17).

A transparência exige que as informações prestadas sejam completas e demonstrem o presente, o passado e o futuro das contas públicas. Segundo Platt Neto et al. (2007), é indispensável para uma boa gestão pública o fornecimento de dados e informações compreensíveis. Estas informações são úteis para a tomada de decisões dos gestores públicos, demonstram os riscos das finanças e também oferecem ao cidadão informações da situação de seu país, estado ou município (FMI, 2007). Na figura 2 , são apresentados os elementos da transparência das contas públicas.

Figura 1 - Elementos da transparência das contas públicas

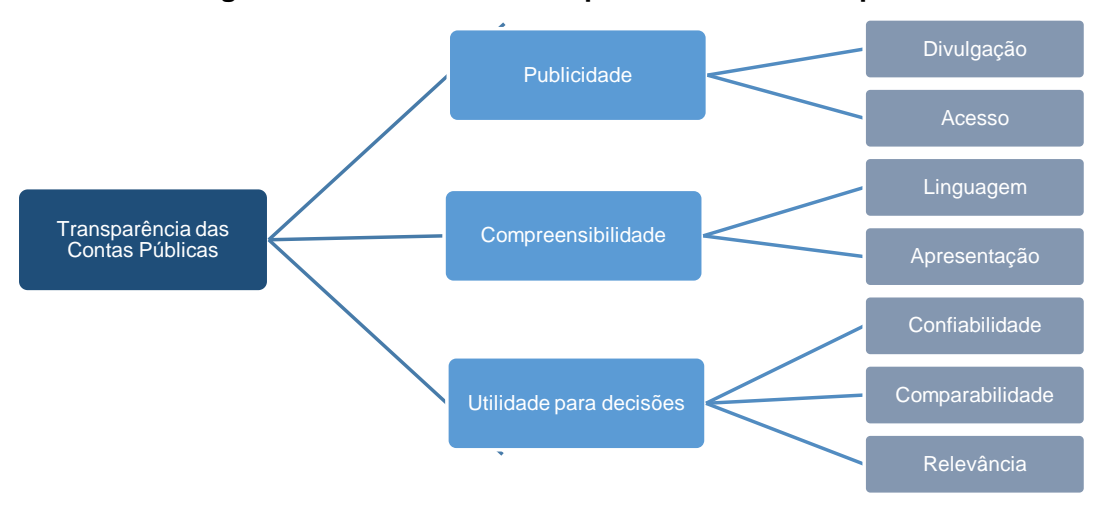

Fonte: Platt Neto et al. (2007, p. 85) 
Para Platt Neto et al. (2007), o alcance da transparência nas contas públicas está atrelado à divulgação e ao acesso a informações confiáveis, comparáveis, relevantes e disponibilizadas em uma linguagem simples e acessível. Jalón et al. (2017) verificaram que há uma grande necessidade de melhoria na transparência e divulgação de informações institucionais, organizacionais e de planejamento, bem como em informações econômicas, orçamentárias e estatísticas nos municípios da Espanha.

Uma alternativa para aumentar a transparência das entidades públicas é a transparência por design, recomendada por Mingo e Cerrillo-i-Martínez (2018). A transparência por design refere-se à incorporação de obrigações de transparência ao longo do ciclo de vida de um registro público, visando garantir acesso público eficiente à informação e assegurar a integridade dos registros e sua rastreabilidade (Mingo \& Cerrillo-i-Martínez, 2018). Essa abordagem propõe a inclusão de metadados nos documentos públicos e pode garantir o gerenciamento adequado desses registros, incluindo a transparência ao longo do seu ciclo de vida. A transparência por design minimiza os riscos de corrupção associados ao gerenciamento das informações criadas pela administração pública.

\subsection{Participação}

A participação ativa e o estabelecimento de ligações claras entre a sociedade e as organizações públicas locais podem criar um comportamento ético sustentável, por parte dos prefeitos e agentes públicos (Erakovich \& Wyman, 2010), transformando a cultura administrativa local e responsabilizando o governo quanto ao alcance das metas estrategicamente estabelecidas (Ruano, 2015).

Quanto maior a participação da sociedade, maior será a transparência dos órgãos públicos (Sacramento \& Pinho, 2007). Kim (2008) defende que a sociedade civil deve estar ativamente envolvida no processo de governança e tomada de decisão, assim como os governantes precisam estar comprometidos com a promoção da transparência e da responsabilização, principalmente no contexto de países em desenvolvimento.
De acordo com Steffek e Ferretti (2009), a participação da sociedade civil e a adoção de procedimentos participativos muitas vezes levam a uma maior transparência, melhorando consequentemente a responsabilidade da governança. Como exemplo, é possível citar os Orçamentos Participativos, que têm o potencial de aumentar a transparência, a responsabilidade democrática e o gerenciamento efetivo das cidades (Brun-Martos \& Lapsley, 2017; Fedozzi \& Martins, 2015), podendo ser considerados um instrumento de promoção da accountability.

A participação dos stakeholders na divulgação de informações públicas pode assegurar a sustentabilidade das práticas de transparência, beneficiando os divulgadores de informações e fornecendo para a sociedade um conteúdo compreensível e relevante (N. F. da Cruz et al., 2016). Diversos estudos foram realizados no campo da accountability, sendo alguns deles destacados na próxima seção.

\section{Procedimentos Metodológicos}

Este estudo tem natureza descritiva com abordagem qualitativa. Para analisar a capacidade de accountability dos portais eletrônicos, foi utilizado o modelo de análise elaborado por Raupp e Pinho (2013). O procedimento técnico utilizado foi a pesquisa documental, tendo como objeto de estudo os portais eletrônicos dos 79 municípios do estado de MS. De acordo com a Secretaria de Estado de Meio Ambiente e Desenvolvimento Econômico SEMADE (2015), o MS é o sexto maior estado do país, com extensão territorial de $357.145,534 \mathrm{~km}^{2}$, com classes populacionais que variam entre 3.000 e 900.000 habitantes.

Como técnica de coleta de dados, foi utilizado o protocolo de busca adaptado nos mesmos moldes de Raupp e Pinho (2013), considerando os indicadores de prestação de contas, transparência e participação. O protocolo de busca foi adaptado para o campo das prefeituras municipais, haja vista que os autores analisaram os portais das câmaras municipais do estado de Santa Catarina, enquanto promotores da construção da accountability. O protocolo utilizado no presente estudo é apresentado no Quadro 2. 
Quadro 2 - Protocolo de busca adaptado para Prefeituras Municipais

\begin{tabular}{|c|c|c|c|}
\hline \multicolumn{4}{|c|}{ Identificação do município } \\
\hline Cidade: & \multicolumn{3}{|l|}{ Número de habitantes: } \\
\hline \multicolumn{4}{|c|}{ Registro de acesso } \\
\hline \multicolumn{4}{|c|}{ Data da busca: $\quad$ Horário da busca: } \\
\hline \multicolumn{4}{|c|}{ Pesquisador Responsável pela busca: } \\
\hline \multicolumn{4}{|c|}{ Dimensão: Prestação de Contas } \\
\hline Capacidade & Indicadores & Presença do item & Observações \\
\hline Nula & $\begin{array}{l}\text { Inexistência de qualquer tipo de relatório e/ou impossibilidade de sua localização (PPA, LDO, LOA, } \\
\text { Relatórios de Gestão e Relatório Resumido da Execução Orçamentária). }\end{array}$ & & \\
\hline Baixa & $\begin{array}{l}\text { Divulgação do conjunto de Relatórios Legais dos gastos incorridos (Relatórios de Gestão, } \\
\text { Demonstrações Contábeis, Licitações, Receitas e Despesas e Folha de Pagamento), de forma parcial } \\
\text { e/ou após o prazo. }\end{array}$ & & \\
\hline Média & Divulgação do conjunto de Relatórios Legais dos gastos incorridos dentro do prazo estabelecido por lei. & & \\
\hline Alta & $\begin{array}{l}\text { Divulgaçãodo conjunto de Relatórios Legais dentro do prazo legal, além de Relatórios complementares } \\
\text { dos gastos incorridos. }\end{array}$ & & \\
\hline \multicolumn{4}{|c|}{ Dimensão: Transparência } \\
\hline Capacidade & Indicadores & Presença do item & Observações \\
\hline Nula & $\begin{array}{l}\text { Inexistência de qualquer tipo de indicador de transparência das atividades prestadas pelos agentes } \\
\text { públicos municipais. }\end{array}$ & & \\
\hline Baixa & Disponibilização da legislação. & & \\
\hline \multirow{3}{*}{ Média } & Carta de serviço ao cidadão da Prefeitura Municipal. & & \\
\hline & Disponibilização da legislação com possibilidade de download. & & \\
\hline & Vídeos informativos. & & \\
\hline \multirow{3}{*}{ Alta } & Divulgação de matérias referentes a tramitações da Prefeitura. & & \\
\hline & TV da Prefeitura. & & \\
\hline & Rádio da Prefeitura. & & \\
\hline \multicolumn{4}{|c|}{ Dimensão: Participação } \\
\hline Capacidade & Indicadores & Presença do item & Observações \\
\hline Nula & Inexistência de qualquer tipo de canal para a participação dos cidadãos. & & \\
\hline \multirow{4}{*}{ Baixa } & E-mail da Prefeitura. & & \\
\hline & E-mail dos setores da Prefeitura. & & \\
\hline & E-mail do Prefeito. & & \\
\hline & Formulário eletrônico. & & \\
\hline \multirow{4}{*}{ Média } & Homepage do Prefeito. & & \\
\hline & Twitter. & & \\
\hline & YouTube. & & \\
\hline & Monitoramento das ações dos usuários. & & \\
\hline \multirow{2}{*}{ Alta } & Ouvidoria. & & \\
\hline & Indicativo de retorno. & & \\
\hline
\end{tabular}

Fonte: Adaptado de Raupp e Pinho (2013).

Inicialmente foi realizada uma busca no site www.google.com.br, para confirmação da existência dos portais eletrônicos de cada município. Após a identificação de cada site, foram realizadas visitas aos portais eletrônicos entre os meses de setembro e outubro de 2017. Os dados foram obtidos através da observação dos portais eletrônicos e do preenchimento do protocolo de busca; sendo posteriormente compilados pelo software Start, versão 3.3. 
Os dados coletados foram validados por dois pesquisadores seniores, e, em seguida, os municípios foram agrupados por classes populacionais. Após classificação dos municípios, foi realizada a análise de conteúdo dos protocolos de busca, para que fosse possível identificar os municípios de acordo com a capacidade de promover a accountability.

$\mathrm{Na}$ análise de conteúdo, foram realizadas as seguintes etapas: fase de pré-exploração do material, envolvendo leituras flutuantes do corpus da pesquisa, seleção das unidades de análise do campo de presença do item e dos comentários de cada protocolo, bem como o processo de categorização/enquadramento de cada município de acordo com o modelo de análise da accountability de Raupp e Pinho (2013).

A capacidade nula dos três indicadores é considerada quando for constatada a inexistência de qualquer tipo de relatório e/ou a impossibilidade de sua localização, assim como a inexistência de qualquer tipo de indicador de transparência e de canal para participação dos cidadãos (Raupp \& Pinho, 2013). A baixa capacidade é indicada para os portais que apresentaram divulgação parcial e/ou após o prazo do conjunto de relatórios legais, detalhamento de seções (ordem do dia, atas das seções), notícias da câmara municipal sobre as atividades dos vereadores, disponibilização de legislação e e-mail da câmara, e-mail de setores da câmara, e-mail do vereador e formulário eletrônico (Raupp \& Pinho, 2013).

Foram considerados de média capacidade, aqueles portais que apresentaram divulgação do conjunto de relatórios legais dos gastos incorridos dentro do prazo legal, que disponibilizaram legislação com possibilidade de download, vídeos das sessões legislativas, homepage do vereador, Twitter, vídeo no YouTube e monitoramento das ações dos usuários (Raupp \& Pinho, 2013). E por fim, a alta capacidade foi atribuída a portais com divulgação do conjunto de relatórios legais e de relatórios complementares dos gastos incorridos, dentro do prazo legal, divulgação das matérias nas fases de tramitação, de vídeos das sessões legislativas ao vivo, além da existência de ouvidoria e de indicativo de retorno (Raupp \& Pinho, 2013).

Após a análise de conteúdo e classificação dos portais eletrônicos quanto à capacidade de promoção da accountability, os resultados foram organizados em tabelas e gráficos, de modo a melhor apresentar os achados.

\section{Resultados e Discussões}

Verificou-se inicialmente que os 79 municípios sul-matogrossenses possuem portal eletrônico oficial. Após a confirmação da existência dos portais eletrônicos, os municípios foram agrupados por classe populacional, dando origem à Tabela 1.

Tabela 1 - Municípios por classe populacional

\begin{tabular}{|c|c|c|c|}
\hline Classe populacional & Municípios & № municípios & $\%$ \\
\hline Até 5.000 habitantes & Figueirão, Taquarussu, Jateí, Novo Horizonte do Sul e Rio Negro & 5 & $6,3 \%$ \\
\hline De 5.001 a 10.000 habitantes & $\begin{array}{l}\text { Alcinopólis, Paraíso das Águas, Rochedo, Corguinho, Douradina, Caracol, Vicentina, } \\
\text { Selviria, Juti, Bandeirantes, Jaraguari, Laguna Carapã, Inocência, Santa Rita do Pardo, } \\
\text { Pedro Gomes, Japorã, Bodoquena, Antonio João, Anaurilândia e Glória de Dourados. }\end{array}$ & 20 & $25,4 \%$ \\
\hline De 10.001 a 20.000 habitantes & $\begin{array}{l}\text { Guia Lopes da Laguna, Sete Quedas, Dois Irmãos do Buriti, Tacuru, Batayporã, Aral } \\
\text { Moreira, Brasilândia, Eldorado, Deodápolis, Angélica, Paranhos, Camapuã, Nioaque, } \\
\text { Água Clara, Coronel Sapucaia, Iguatemi, Porto Murtinho, Sonora, Mundo Novo, Fátima } \\
\text { do Sul, Rio Verde de Mato Grosso e Costa Rica }\end{array}$ & 22 & $27,9 \%$ \\
\hline De 20.001 a 50.000 habitantes & $\begin{array}{l}\text { Nova Alvorada do Sul, Terenos, Itaquiraí, Bonito, Cassilândia, Amambai, Bataguassu, } \\
\text { Ladário, Ivinhema, Itaporã, Chapadão do Sul, Ribas do Rio Pardo, Bela Vista, } \\
\text { Anastácio, Aparecida do Tabuado, São Gabriel do Oeste, Jardim, Miranda, Caarapó, } \\
\text { Coxim, Rio Brilhante, Paranaíba, Maracaju e Aquidauana }\end{array}$ & 24 & $30,4 \%$ \\
\hline De 50.001 a 100.000 habitantes & Naviraí, Nova Andradina, Ponta Porã e Sidrolândia & 4 & $5,1 \%$ \\
\hline De 100.001 a 300.000 habitantes & Corumbá, Dourados e Três Lagoas & 3 & $3,8 \%$ \\
\hline De 300.001 a 900.000 habitantes & Campo Grande & 1 & $1,3 \%$ \\
\hline Total & & 79 & $100,0 \%$ \\
\hline
\end{tabular}

Verifica-se, com base na Tabela 1, que 59,4\% dos municípios possuem até 20.000 habitantes e $89,8 \%$ possuem até 50.000 habitantes, ou seja, o estado do MS é formado por municípios de pequeno porte, considerando o aspecto demográfico. Após classificação dos municípios de acordo com as classes populacionais, foram realizadas as análises de conteúdo dos 948 itens levantados nos protocolos de busca, considerando todos os municípios de MS.

Ao analisar os 79 portais eletrônicos, observou-se falta de padronização e razoável complexidade na forma de divulgação das informações, dificultando o acesso do cidadão que deseja exercer o seu direito constitucional. Nota-se que, assim como verificado por Bernardes et al. (2015), a forma de organização dos portais eletrônicos dificulta o acesso às informações, principalmente para os cidadãos que não estão familiarizados com o site, podendo até inviabilizar o acesso às informações.

De modo geral, os portais possuem um local específico denominado "Portal da Transparência", que utilizam diferentes programas gerenciadores da informação, tais como o eTransparência, o Transparência Fly e Ágili Cidade Digital, todos 
voltados à divulgação de informações de forma clara e objetiva. Contudo, vários portais ocultam informações ou criam caminhos de localização confusos e/ou com letras pequenas, o que torna árdua a busca e a participação do cidadão.

Visando detalhar a capacidade de accountability dos portais analisados, os resultados foram desdobrados em três subtópicos envolvendo a capacidade de Prestação de Contas, a Transparência e a Participação.

\subsection{Prestação de Contas nos Portais do MS}

A prestação de contas, além de uma obrigação legal, deve ser considerada pelos gestores como uma ferramenta para melhorar a gestão pública e reduzir a percepção de corrupção por parte da sociedade (Brusca et al., 2017), no sentido de promover uma cultura de accountability. A capacidade de promoção da accountability por meio da dimensão prestação de contas é apresentada no Gráfico 1.

Gráfico 1 - Capacidade de Prestação de Contas nos municípios do MS

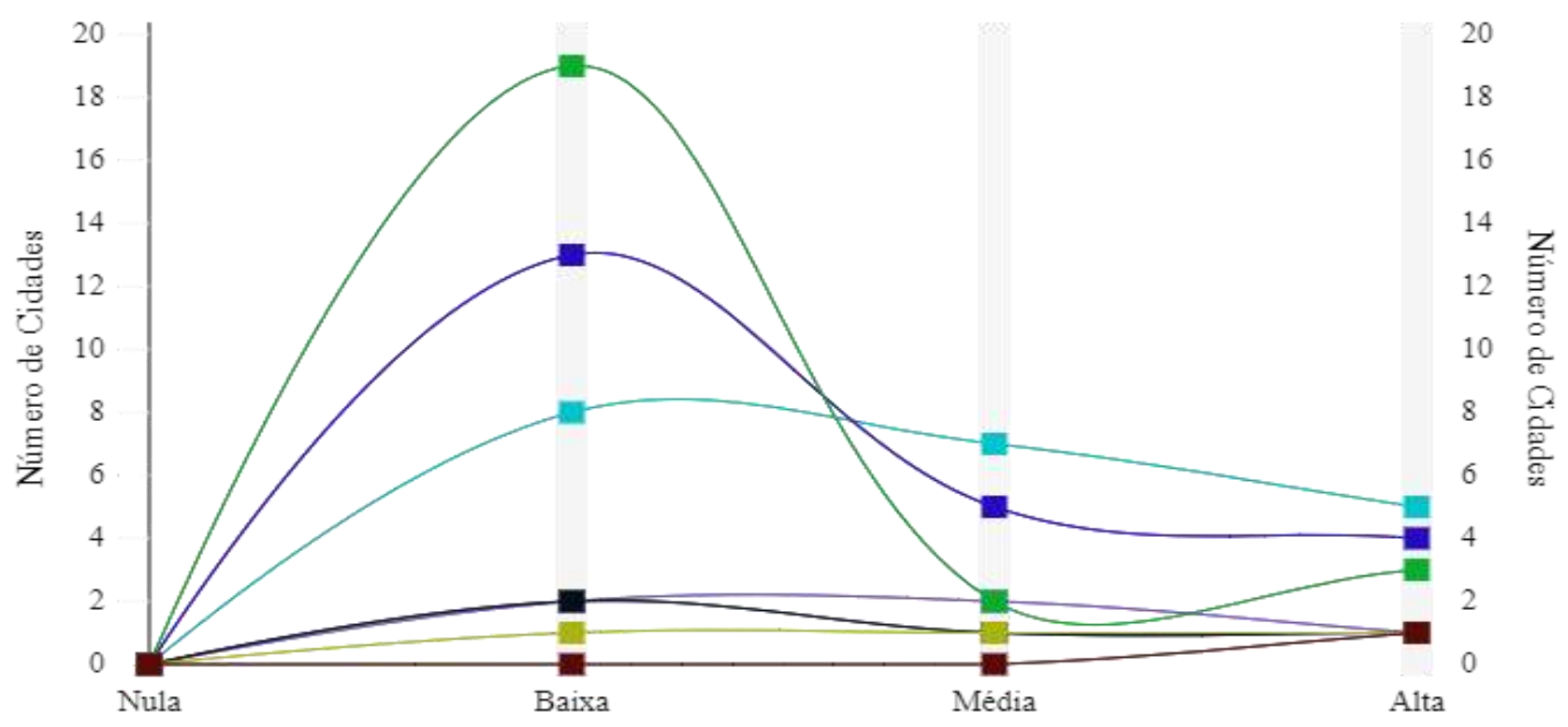

De 300.001 a 900.000 habitantes De 20.001 a 50.000 habitantes

Até 5.000 habitantes

\section{Capacidade \\ De 100.001 a 300.000 habitantes \\ De 10.001 a 20.000 habitantes \\ De 50.001 a 100.000 habitantes \\ De 5.001 a 10.000 habitantes}

O Gráfico 1 demonstra que $56,96 \%$ dos portais apresentam baixa capacidade de prestação de contas, ou seja, 45 de um total de 79 municípios não prestam contas dos gastos das prefeituras. Porém, os municípios de Figueirão, Rochedo, Selviria, Santa Rita do Pardo, Pedro Gomes, Bodoquena, Guia Lopes da Laguna, Dois Irmãos do Buriti, Brasilândia, Costa Rica, Bataguassu, Caarapó, Rio Brilhante, Nova Andradina, Dourados e Campo Grande apresentam alta capacidade de prestação de contas, haja vista que divulgam, além do conjunto de Relatórios Legais, Relatórios complementares dos gastos públicos.

Esses achados representam uma realidade de divulgação do conjunto de Relatórios Legais dos gastos incorridos pelas prefeituras municipais, de forma parcial e/ou após o prazo, corroborando com Agostineto e Raupp (2010), no sentido de que a dimensão da prestação de contas ainda não é uma realidade instituída. Este mesmo aspecto foi observado por Raupp (2014a), nos executivos municipais de Santa Catarina, e também por Simelio et al. (2017) e Jalón et al. (2017), na Espanha.

Além da baixa capacidade de prestar contas da maioria dos portais municipais do MS, verifica-se que os municípios com classes populacionais menores prestam menos contas à população, diferindo dos achados de Raupp e Pinho (2013) que verificaram baixa capacidade dos portais das câmaras municipais de Santa Catarina, independente da classe populacional.

\subsection{Transparência nos Portais do MS}

Partindo da premissa de que a transparência deve ser considerada como um valor central e uma prioridade no relacionamento do governo com a sociedade (Cooper, 2004), os portais do MS foram analisados. A capacidade de promover a accountability por meio da dimensão transparência é apresentada em síntese no Gráfico 2. 
Gráfico 2 - Transparência nos Portais do MS

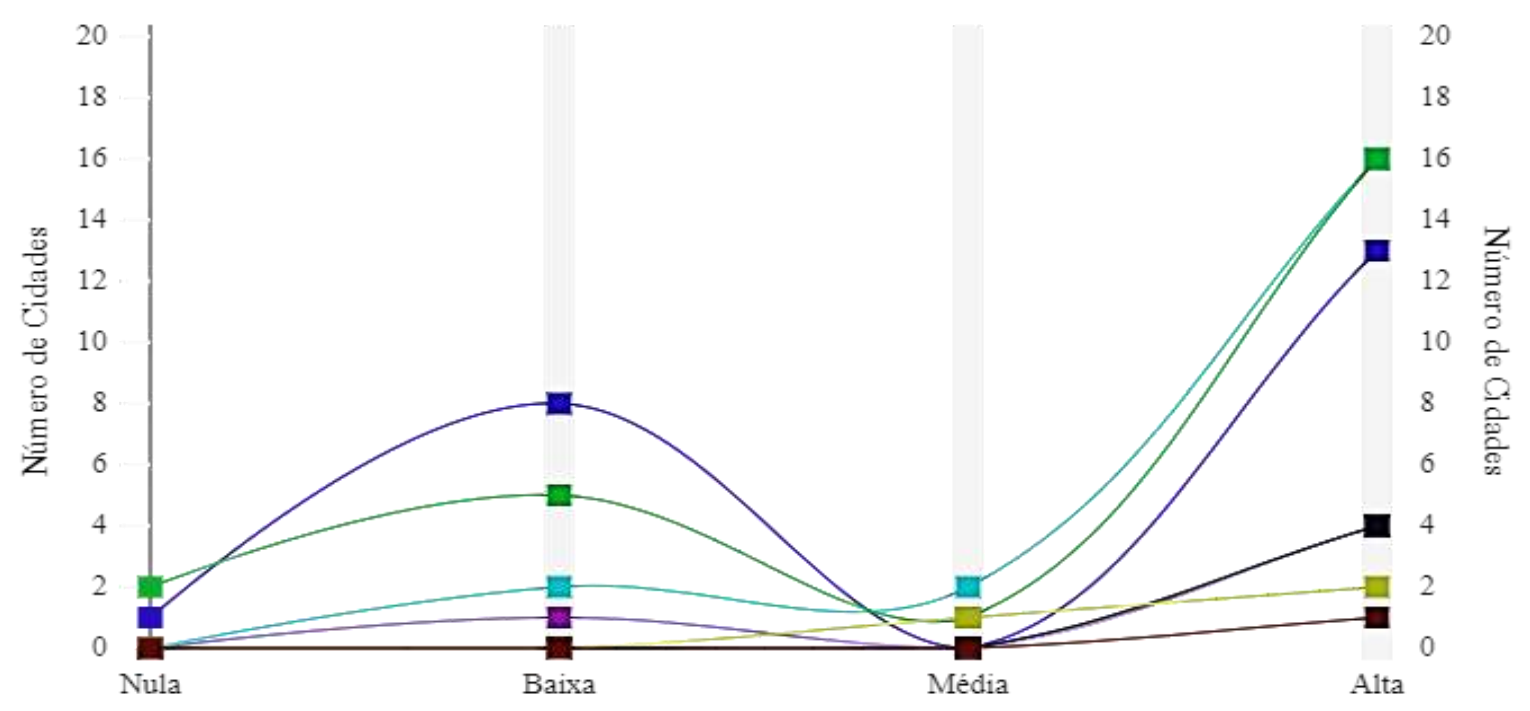

Capacidade

De 300.001 a 900.000 habitantes De 20.001 a 50.000 habitantes Até 5.000 habitantes
No que se refere à transparência, $70,89 \%$ dos portais eletrônicos apresentam capacidade alta de promover a accountability. Verificou-se que a legislação municipal é disponibilizada para a sociedade, inclusive com possibilidade de download, que as matérias tramitadas são divulgadas por meio de vídeos, rádio e TV municipal e que a maioria dos municípios apresenta a carta de serviço ao cidadão.

Contudo, $20,25 \%$ dos portais apresentam baixa capacidade (Rio Negro, Alcinópolis

Japorã, Tacuru, Batayporã, Camapuã, Água Clara, Porto Murtinho, Sonora, Fátima do Sul, Rio Verde de Mato Grosso, Amambai, Itaporã, Miranda, Rio Brilhante e Maracaju), pois disponibilizam apenas a legislação municipal. Por outro lado, 3,8\% dos sites apresentam capacidade nula de transparência (Aquidauana, Aral Moreira e Bela Vista), ou seja, inexiste qualquer tipo de indicador de transparência das atividades prestadas pelos agentes públicos municipais.

Nota-se um avanço em termos de transparência, pois a maioria dos municípios apresenta alta capacidade, contudo, alguns portais ainda apresentam capacidade baixa e nula, demonstrando que o cenário de baixa transparência identificado por $\mathrm{C}$. F. Cruz et al. (2012), em Santa Catarina, por C. F. Cruz et al. (2009), no estado do Rio de Janeiro, por Sacramento e Pinho (2007), na Bahia, e por
Andrade et al. (2017), nas maiores cidades brasileiras, também está presente em parte dos municípios do MS.

De modo geral, as prefeituras utilizam as mídias sociais para se comunicarem com a sociedade, contribuindo para maior transparência dos executivos municipais, conforme sugerido por Picazo-Vela, Gutiérrez-Martínez e Luna-Reyes (2012). Porém, há espaço para aumentar a transparência por meio do uso das redes sociais, tais como Facebook, Instagram, Twitter, entre outras, que no contexto atual têm amplo alcance da sociedade.

\subsection{Participação nos Portais do MS}

A participação ativa e o estabelecimento de ligações claras entre a sociedade e as organizações públicas locais oferecem benefícios para a sociedade (Erakovich \& Wyman, 2010). Nesse sentido, foi verificada a existência de canais de comunicação que promovam participação dos cidadãos, tais como e-mail da prefeitura e seus setores, formulários eletrônicos, homepage do Prefeito, Twitter, Vídeos no YouTube, monitoramento das ações dos usuários, existência de ouvidoria e de indicativo de retorno. Os resultados estão dispostos no Gráfico 3. 
Gráfico 3 - Participação nos Portais do MS

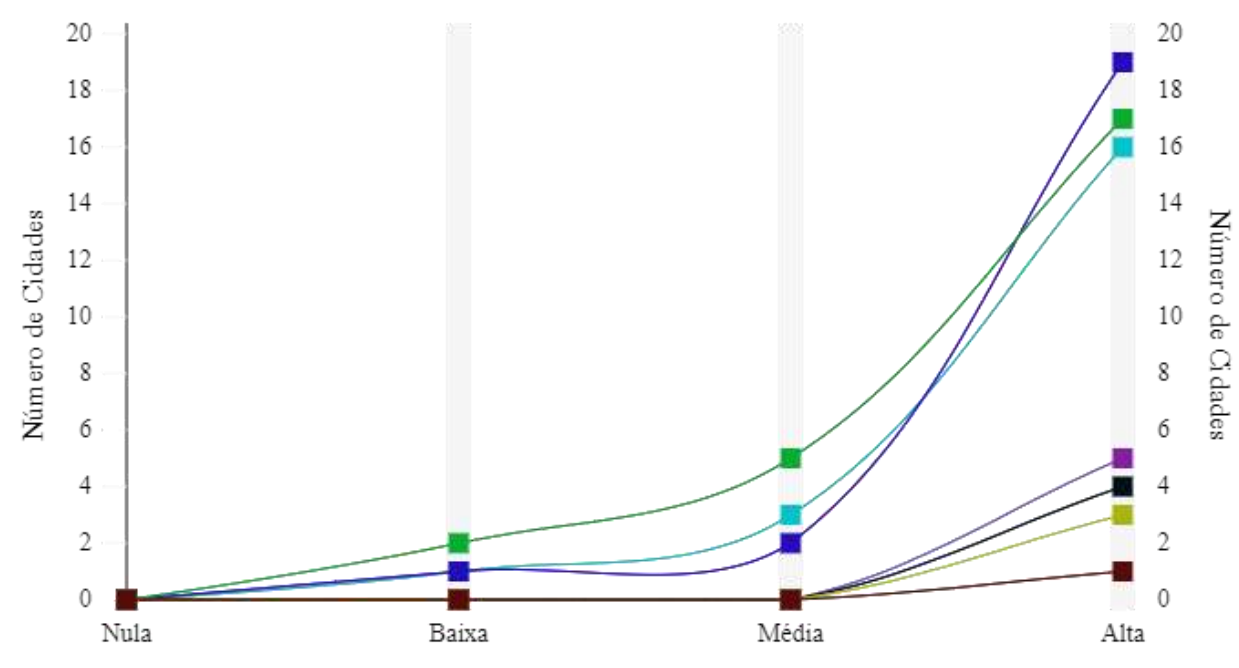

Capacidade

De 300.001 a 900.000 habitantes 100.001 a 300.000 habitantes De 50.001 a 100.000 habitantes De 20.001 a 50.000 habitantes $=$ De 10.001 a 20.000 habitantes $=$ De 5.001 a 10.000 habitantes

Até 5.000 habitantes

Quanto à capacidade de participação, o estado do MS apresenta um índice de $82,28 \%$ de portais municipais com alta capacidade, ou seja, 65 dos 79 municípios analisados possuem mecanismos que oferecem a possibilidade de participação e interação da sociedade com as prefeituras municipais. Essa predominância indica que, de modo geral, os canais de participação ao cidadão promovem condições para a construção da accountability no estado. Os achados no MS diferem dos resultados de Raupp e Pinho (2013), nos quais a maioria dos portais apresentou baixa capacidade na dimensão de participação.

\subsection{Síntese das evidências de accountability nos portais do MS}

A síntese das evidências de prestação de contas, transparência e participação na construção da accountability no MS, verificadas a partir da análise dos portais eletrônicos, é apresentada na Tabela 2.

Tabela 2 - Síntese das Dimensões Analisadas

\begin{tabular}{|c|c|c|c|c|c|c|c|c|c|c|c|c|}
\hline \multirow{2}{*}{ Classe Populacional } & \multicolumn{4}{|c|}{ Prestação de Contas } & \multicolumn{4}{|c|}{ Transparência } & \multicolumn{4}{|c|}{ Participação } \\
\hline & Nula & Baixa & Média & Alta & Nula & Baixa & Média & Alta & Nula & Baixa & Média & Alta \\
\hline Até 5.000 habitantes & 0 & 2 & 2 & 1 & 0 & 1 & 0 & 4 & 0 & 0 & 0 & 5 \\
\hline $\begin{array}{l}\text { De } 5.001 \text { a } 10.000 \\
\text { habitantes }\end{array}$ & 0 & 8 & 7 & 5 & 0 & 2 & 2 & 16 & 0 & 1 & 3 & 16 \\
\hline $\begin{array}{l}\text { De } 10.001 \text { a } 20.000 \\
\text { habitantes }\end{array}$ & 0 & 13 & 5 & 4 & 1 & 8 & 0 & 13 & 0 & 1 & 2 & 19 \\
\hline $\begin{array}{l}\text { De } 50.001 \text { a } 100.000 \\
\text { habitantes }\end{array}$ & 0 & 2 & 1 & 1 & 0 & 0 & 0 & 4 & 0 & 0 & 0 & 4 \\
\hline $\begin{array}{l}\text { De } 100.001 \text { a } 300.000 \\
\text { habitantes }\end{array}$ & 0 & 1 & 1 & 1 & 0 & 0 & 1 & 2 & 0 & 0 & 0 & 3 \\
\hline $\begin{array}{l}\text { De } 300.001 \text { a } 900.000 \\
\text { habitantes }\end{array}$ & 0 & 0 & 0 & 1 & 0 & 0 & 0 & 1 & 0 & 0 & 0 & 1 \\
\hline Total & 0 & 45 & 18 & 16 & 3 & 16 & 4 & 56 & 0 & 4 & 10 & 65 \\
\hline
\end{tabular}

Dos 79 portais municipais analisados, 18,99\% apresentam alta capacidade em todas as dimensões, sendo eles: Figueirão, Rochedo, Selvíria, Santa Rita do Pardo, Pedro Gomes, Bodoquena, Guia Lopes da Laguna, Dois Irmãos do Buriti, Brasilândia, Costa Rica, Bataguassu, Caarapó, Nova Andradina, Dourados e Campo Grande. Apenas o município Paraíso das Águas apresenta média capacidade em todas as dimensões. O município de Fátima do Sul apresentou baixa capacidade nas dimensões de prestação de contas e de transparência e média capacidade de participação, portanto precisa melhorar significativamente o seu portal eletrônico para promover a accountability no município.

Tais evidências permitem inferir que as prefeituras municipais não estão cumprindo a legislação de maneira adequada e efetiva no que diz respeito à prestação de contas, visto que essa dimensão da accountability está prevista direta ou indiretamente na Lei de Responsabilidade Fiscal, na Lei da Transparência e na Lei de 
Acesso a Informação. Esta é uma das principais contribuições deste estudo, haja vista que as prefeituras, além de cumprir a legislação, devem prestar contas visando estabelecer uma cultura de accountability, exprimindo pelas suas Demonstrações Financeiras de que forma os recursos estão sendo arrecadados e, principalmente, aplicados no município.

Quanto à dimensão da transparência, verificou-se que a maioria dos portais eletrônicos do MS demonstra preocupação sobre a comunicação com a sociedade, pois divulga a legislação municipal e utiliza os canais de comunicação para informar as atividades que são tramitadas internamente. No que diz respeito à participação, os portais eletrônicos do MS apresentam canais de comunicação diretos e condições para que a sociedade apresente suas críticas, elogios, sugestões e dúvidas, seja pelas redes sociais, por e-mails ou pela ouvidoria. Essa postura transparente e aberta dos municípios favorece a promoção da accountability e pode resultar em maior participação da sociedade no exercício da cidadania.

\section{Considerações Finais}

O presente estudo teve por objetivo verificar a capacidade de accountability dos portais eletrônicos dos municípios do estado do Mato Grosso do Sul. As principais contribuições do estudo residem na identificação de que a maioria dos municípios não utiliza os portais eletrônicos para prestar contas. Esse resultado corrobora com Jalón et al. (2017) haja vista que, assim como na Espanha, no MS também existe a necessidade de melhoria na prestação de contas, envolvendo, principalmente, as informações econômicas, orçamentárias, estatísticas e institucionais dos municípios. No tocante à transparência, $70,89 \%$ dos portais apresentam alta capacidade de promover a accountability, contudo, cabe ressaltar que não foi objeto de análise a clareza, a qualidade e a efetividade dos mecanismos e das informações divulgadas nos portais, sendo essa uma limitação deste estudo.

Com relação à participação, $82,28 \%$ dos portais possuem alta capacidade de promover a accountability no estado, entretanto, destacamos que os resultados aqui evidenciados demonstram a possibilidade de participação, não podendo ser entendidos como participação efetiva da sociedade no gerenciamento das cidades, como recomendado por Steffek e Ferretti (2009) e por Brun-Martos e Lapsley (2017).

As evidências permitem inferir que, nas dimensões da transparência e da participação, os portais apresentam bons resultados para a construção da accountability. Contudo, quanto à prestação de contas, a maioria das prefeituras municipais não cumpre a legislação efetivamente e tampouco divulgam informações financeiras com enfoque nos stakeholders, demonstrando que ainda há um longo caminho a ser percorrido para que de fato exista uma cultura de accountability no MS. Uma explicação para esse problema pode ser a falta de comprometimento dos governantes com a promoção da transparência e da responsabilização mencionados por Kim (2008).

Sugere-se que sejam realizados estudos futuros que abarquem uma análise estatística, comparando a capacidade de promoção de accountability com as variáveis socioeconômicas de cada município, no sentido de verificar se tais aspectos impactam nas dimensões da accountability. Recomenda-se também que seja analisada, em profundidade, a utilização das mídias modernas tais como Facebook, Twitter e Instagram como instrumentos de promoção da accountability, principalmente pelo amplo alcance e potencial de interação que essas mídias representam para a sociedade contemporânea.

\section{Referências}

Agostineto, R. C., \& Raupp, M. F. (2010). Prestação de Contas por meio de portais eletrônicos: Um estudo em Câmaras municipais da grande Florianópolis. Revista Universo Contábil, 13(3), 64-79.

Andersen, T. B. (2009). E-Government as an anti-corruption strategy. Information Economics and Policy, 21(3), 201-210.

Andrade, R. G. de, Raupp, M. F., \& Pinho, J. A. G. (2017). Em Busca Da Transparência Ativa Em Câmaras: Uma investigação nos maiores municípios brasileiros. Advances in Scientific and Applied Accounting, 10(1), 3-20.

Bairral, M. A. da C., Silva, A. H. C. e, \& Alves, F. J. dos S. (2015). Transparência no setor público: uma análise dos relatórios de gestão anuais de entidades públicas federais no ano de 2010. Revista de Administração Pública, 49(3), 643-675.

Bernardes, M. B., Santos, P. M., \& Rover, A. J. (2015). Ranking das prefeituras da região Sul do Brasil: uma avaliação a partir de critérios estabelecidos na Lei de Acesso à Informação. Revista de Administração Pública, 49(3), 761-792.

Beuren, I. M., \& Söthe, A. (2009). A teoria da legitimidade e o custo político nas evidenciações contábeis dos governos estaduais na região sudeste do Brasil. Revista de Contabilidade e Organizações, 3(5), 98-120.

Braga, L. V., Alves, W. S., Figueiredo, R. M. da C., \& Santos, R. R. dos. (2008). O papel do Governo Eletrônico no fortalecimento da governança do setor público. Revista Do Serviço Público, 59(1), 5-21.

Brun-Martos, M. I., \& Lapsley, I. (2017). Democracy, governmentality and transparency: participatory budgeting in action. Public Management Review, 19(7), 1006-1021.

Brusca, I., Rossi, F. M., \& Aversano, N. (2017). Accountability and Transparency to Fight against Corruption: An International Comparative Analysis. Journal of Comparative Policy Analysis: Research and Practice, 00(00), 1-19.

Campos, A. M. (1990). Accountability: Quando poderemos traduzi-la para o português? Revista de Administração Pública, 24(2), 30-50.

Constituição da República Federativa do Brasil. (2006). Texto constitucional promulgado em 05 de outubro de 1988. Brasilia-DF: Senado Federal Subsecretaria de Edições Técnicas.

Cooper, T. L. (2004). Big Questions in Administrative Ethics: A Need for Focused, Collaborative Effort. Public Administration Review, 64(4), 395-407.

Cruz, C. F., Ferreira, A. C. D. S., Silva, L. M. Da, \& Macedo, M. Á. D. S. (2012). Transparência da gestão pública municipal: um estudo a partir dos portais eletrônicos dos maiores municípios brasileiros. Revista de Administração Pública, 46(1), 153-176.

Cruz, C. F., Silva, L. M., \& Santos, R. (2009). Transparência da gestão fiscal: um estudo a partir dos portais eletrônicos dos maiores municípios do Estado do Rio de Janeiro. Contabilidade, Gestão e Governança, 12(3), 102-115.

Cruz, N. F. da, \& Marques, R. C. (2014). Scorecards for sustainable local governments. Cities, 39, 165-170.

Cruz, N. F. da, Tavares, A. F., Marques, R. C., Jorge, S., \& de Sousa, L. (2016). Measuring Local Government Transparency. Public Management Review, 18(6), 866-893.

Dantas, J. A., Zendersky, H. C., \& Niyama, J. K. (2005). A dualidade entre os benefícios do disclosure e a relutância das organizações em aumentar o grau de evidenciação. Economia e Gestão, 5(11), 56-76.

Erakovich, R., \& Wyman, S. (2010). The Imperative for Building Value Reciprocity Between Society and City Hall: Implications for Local Government Ethics Building in Serbia and Montenegro. International Journal of Public Administration, 33(10), 499-507.

Fedozzi, L. J., \& Martins, A. L. B. (2015). Trajetória do orçamento participativo de Porto Alegre: representação e elitização política. Lua Nova: Revista de Cultura e Política, (95), 181-224.

Hwang, J., \& Akdede, S. H. (2011). The influence of governance on public sector efficiency: A cross-country analysis. Social Science Journal, 48(4), 735-738.

Jalón, M. L. D., Heras, E. N., \& Agudo, L. M. (2017). Cumplimiento de los requisitos de transparencia: un diagnóstico de la situación para los municipios 
españoles de más de 50.000 habitantes. Innovar, 27(66), 109-121.

Janssen, M., Charalabidis, Y., \& Zuiderwijk, A. (2012). Benefits, Adoption Barriers and Myths of Open Data and Open Government. Information Systems Management, 29(4), 258-268.

Kim, P. S. (2008). A daunting task in Asia: The move for transparency and accountability in the Asian public sector. Public Management Review, 10(4), $527-537$.

Koppell, J. G. S. (2005). Pathologies of accountability: ICANN and the challenge of "Multiple Accountabilities Disorder." Public Administration Review, 65(1), 94-108.

Lei Complementar $n^{\circ} 131$, de 27 de maio de 2009. (2009). Acrescenta dispositivos à Lei Complementar $n^{\circ} 101$, de 4 de maio de 2000, que estabelece normas de finanças públicas voltadas para a responsabilidade na gestão fiscal e dá outras providências, a fim de determinar a disponibilização, em tempo real, de infor. Retrieved from http://www.planalto.gov.br/ccivil_03/leis/lcp/lcp131.htm

Lei Complementar $n^{\circ} 101$, de 4 de maio de 2000. (2000). Estabelece normas de finanças públicas voltadas para a responsabilidade na gestão fiscal e dá outras providências. Retrieved from http://www.planalto.gov.br/ccivil_03/leis/LCP/Lcp101.htm

Lei Complementar $n^{\circ} 12.527$, de 18 de novembro de 2011. (2011). Regula o acesso a informações previsto no inciso XXXIII do art. $5^{\circ}$, no inciso II do $\S 3^{\circ}$ do art. 37 e no $\$ 2^{\circ}$ do art. 216 da Constituição Federal; altera a Lei $n^{\circ} 8.112$, de 11 de dezembro de 1990; revoga a Lei $n^{\circ} 11.111$, de 5 de maio de 2005 , e dispositiv. Retrieved from http://www.planalto.gov.br/ccivil_03/_ato20112014/2011/lei/l12527.htm

Licht, J. de F. (2014). Policy Area as a Potential Moderator of Transparency Effects: An Experiment. Public Administration Review, 74(3), 361-371.

Lupu, D., \& Lazăr, C. G. (2015). Influence of e-government on the Level of Corruption in some EU and Non-EU States. Procedia Economics and Finance, 20, 365-371.

Mingo, A. C. de, \& Cerrillo-i-Martínez, A. (2018). Improving records management to promote transparency and prevent corruption. International Journal of Information Management, 38(1), 256-261.

Mutiganda, J. C. (2013). Budgetary governance and accountability in public sector organisations: An institutional and critical realism approach. Critical Perspectives on Accounting, 24(7-8), 518-531.

Oliveira, A. G. de, \& Pisa, B. J. (2015). IGovP: índice de avaliação da governança pública - instrumento de planejamento do Estado e de controle social pelo cidadão. Revista de Administração Pública, 49(5), 1263-1290.

Picazo-Vela, S., Gutiérrez-Martínez, I., \& Luna-Reyes, L. F. (2012). Understanding risks, benefits, and strategic alternatives of social media applications in the public sector. Government Information Quarterly, 29(4), 504-511.

Pinho, J. A. G. De. (2008). Investigando portais de governo eletrônico de estados no Brasil: muita tecnologia, pouca democracia. Revista de Administração Pública, 42(3), 471-493.

Pinho, J. A. G. de, \& Sacramento, A. R. S. (2009). Accountability: já podemos traduzi-la para o português? Revista de Administração Pública, 43(6), 13431368.

Platt-Neto, O. A., Cruz, F. Da, Ensslin, S. R., \& Ensslin, L. (2007). Publicidade e Transparência das Contas Públicas: Obrigatoriedade e abrangência desses principios na administração pública brasileira. Contabilidade Vista \& Revista,
18(1), 75-94.

Raupp, F. M. (2010). Prestação de Contas a partir da Lei da Transparência: um Estudo em Câmaras Municipais de Santa Catarina. In Anais do XVII Congresso Brasileiro de Custos (pp. 1-15). Belo Horizonte-MG.

Raupp, F. M. (2011). Modelo de análise da capacidade dos portais eletrônicos de Câmaras Municipais em construir condições para a Accountability. In Anais do XIV Simpósio de Administração da Produção, Logística e Operações Internacionais (pp. 1-16). São P: FGV-EAESP.

Raupp, F. M. (2014a). Prestação de Contas de Executivos Municipais de Santa Catarina: uma Investigação nos Portais Eletrônicos. Administração Pública e Gestão Social, 6(3), 151-158.

Raupp, F. M. (2014b). Procurando transparência, prestação de contas e participação nos portais eletrônicos de Câmaras Municipais das maiores capitais brasileiras. Revista Iberoamericana de Estudios Municipales - RIEM 5(9), 101-121.

Raupp, F. M. (2016). Realidade da transparência passiva em prefeituras dos maiores municípios brasileiros. Revista ContemporâNea de Contabilidade, 13(30), 34-52.

Raupp, F. M., \& Pinho, J. A. G. de. (2013). Accountability em câmaras municipais: uma investigação em portais eletrônicos. RAUSP - Revista de Administração, 48(4), 770-782.

Rocha, A. C. (2013). A realização da accountability em pareceres prévios do Tribunal de Contas de Santa Catarina. Revista de Administração Pública, 47(4), 901-926.

Rodríguez-Bolívar, M. P., Navarro-Galera, A., \& Alcaide-Muñoz, L. (2015). Governance, transparency and accountability: An international comparison. Journal of Policy Modeling, 37(1), 136-174

Ruano, J. M. (2015). Local Strategic Planning in Spain. a Case Study. Transylvanian Review of Administrative Sciences, (Special), 71-85.

Sacramento, A. R. S., \& Pinho, J. A. G. (2007). Transparência na Administração Pública: O que mudou depois da Lei da Responsabilidade Fiscal? Um estudo exploratório em seis municípios da Região Metropolitana de Salvador. Revista de Contabilidade Da UFBA, 1(1), 48-61.

SEMADE - Secretaria de Estado de Meio Ambiente e Desenvolvimento Econômico. (2015). Perfil estatístico de Mato Grosso do Sul. Campo Grande - MS. Retrieved from http://www.semade.ms.gov.br/wp content/uploads/sites/20/2015/12/Perfil-Estatistico-de-MS-2015-revisao.pdf

Shim, D. C., \& Eom, T. H. (2008). E-Government and Anti-Corruption: Empirical Analysis of International Data. International Journal of Public Administration, 31(3), 298-316.

Simelio, N., Ginesta, X., Vela, J. de S. E., \& Corcoy, M. (2017). Journalism, transparency and citizen participation: a methodological tool to evaluate information published on municipal websites. Information Communication and Society, 4462(October), 1-17.

Steffek, J., \& Ferretti, M. P. (2009). Accountability or "good decisions"? The competing goals of civil society participation in international governance. Global Society, 23(1), 37-57.

Torres, L., Pina, V., \& Acerete, B. (2006). E-Governance Developments in European Union Cities: Reshaping Government's Relationship with Citizens. Governance, 19(2), 277-302. 